\title{
Molecular Manufacturing for Clean, Low Cost Textile Production
}

David R. Forrest, Sc.D., P.E.

Naval Surface Warfare Center, West Bethesda, Maryland USA

and

Institute for Molecular Manufacturing, Los Altos, California USA

\begin{abstract}
Molecular manufacturing is an emerging technology that is being developed to build large objects to atomic precision, quickly and cheaply, with virtually no defects. When it matures, it promises to be an energy efficient and environmentally benign way to make textiles and textile products.
\end{abstract}

Current efforts to apply nanotechnology to textiles promise exciting innovations such as

- Lightweight nanotube fibers stronger than steel

- Fabrics able to sense temperature and control their breathability

- Clothing able to sense injury and provided immediate delivery of medication to a wounded soldier

However, molecular manufacturing will provide atomic control over the structure of a fabric, promising revolutionary changes far beyond current advances:

- A garment could programmably increase or decrease its own size as needed

- A fabric could change its own color and patterns on demand

- The breathability of a textile could be variable and self-regulating

- By integrating molecular robotic components into the material, a fabric could be made to be self-cleaning and self-repairing

- A fabric could be programmed to move on its own accord, creating effects such as a flag flapping even without a breeze

- Molecular fasteners could create new clothing design options for truly seamless garments.

This paper summarizes recent advances in molecular manufacturing that are enabling the development of this radical new vision for the future of textile design and manufacture. 


\section{BACKGROUND}

Although the term "nanotechnology" is now used to describe a broad and diverse range of technological areas, it was originally used to describe a novel method of

manufacturing first articulated by Richard Feynman: that molecular machines should be able to build substances by mechanically placing each atom into position exactly as specified [1]. More recently, Eric Drexler has provided a compelling vision of how massively parallel arrays of molecular assemblers could build large, atomically precise objects cheaply and quickly [2-5]. The envisioned products of these molecular manufacturing systems include:

- powerful desktop computers with a billion processors

- abundant energy with inexpensive, efficient solar energy systems

- cures for serious diseases using nanorobots smaller than cells

- new materials 100 times stronger than steel

- a clean environment with nanomachines to scavenge pollutants

- more molecular manufacturing systems (they could build copies of themselves)

Since 1986 this vision of molecular nanotechnology has captured the public's imagination and is now an integral part of popular culture. References to nanomachines are standard fare in many well-known science fiction books, movies, and television shows. Encyclopedias and children's books feature Drexler's colorful and atomicallyaccurate designs of molecular gears and bearings, as well as artist's renditions of (often fanciful) nanomedical devices cleaning a blocked artery or killing a virus. Today's generation is expecting some form of this vision to happen in their lifetime.

By contrast, the scientific community has been less than embracing of these ideas. Some scientists claim that this technology is either so distant in the future that we need not concern ourselves, or fundamentally impossible and will never happen. The engineering community has been for the most part silent about the controversy, which is really quite interesting because the proposed technology has very little to do with new science and everything to do with engineering analysis, design, and construction.

My assessment is that although progress is slower than it could be if we had some more focused efforts, there have been significant advances and we will likely see a functioning molecular manufacturing system by the year 2015. In this paper I provide a brief synopsis of the molecular manufacturing vision, show that recent advances and new tools have brought us past the threshold of the era of molecular machines, and offer a rather modest vision of what the textile community could do with a desktop manufacturing system that can precisely tailor the molecular structure of a fabric and create inexpensive textile products with imbedded:

- nanocomputers and molecular memory

- nanosensors

- micro- and nanomotors and actuators

- solar energy collectors
- wireless receivers and transmitters

- micro and nano-plumbing

- video displays

- $\quad$ energy storage devices 


\section{MOLECULAR MANUFACTURING}

Molecular manufacturing is a method conceived for the massively parallel processing of individual molecules to fabricate large atomically-exact products. It would rely on the use of many trillions of molecular robotic subsystems working in parallel to process simple chemicals into new materials and devices. Built to atomic specification, the manufactured products would exhibit significantly higher performance than that of today's products. Equally as important, the high level of automation of the manufacturing process would significantly lower the cost compared against today's techniques. A distinguishing feature of molecular manufacturing would be that the trajectory and orientation of every molecule in the system are precisely controlled during the manufacturing operation, differentiating it from processes based on solution chemistry where molecules bump against each other in random orientations until reactions occur.

A few of the key concepts from the principal reference, Nanosystems, are summarized in Figures 1-3. Figure 1 shows a cylindrical bearing, a differential gear, and a schematic of a molecular sorting and conveyor transport system. The design and performance of the first two mechanical parts have been studied in detail, and show that high efficiencies are possible when complementary atomic surfaces are properly matched. Figure 2 shows a schematic of a stiff robotic arm composed of about four million atoms. Simple hydrocarbon molecules are fed to its tip through an internal conveyor system; atoms are transferred from those molecules to the workpiece at processing speeds approaching 500,000 atoms/second - about the speed of a fast enzyme. The other diagram shows how assembly stations could be arranged to construct small components at the denselybranched tips and the feed those products into successively larger sub-assemblies. Figure 3 shows a conceptual diagram of a desktop molecular manufacturing system. Simple hydrocarbon molecules are sorted, attached to conveyors, positioned, and then reacted to build up atomically exact structures.

It is particularly appropriate to be discussing this technology with the textile community audience at Ecotextile 04. Of all the manufactured products that come to mind, there is no better analogy to molecular manufacturing than the production of textiles, which assembles tonnage quantities of material from small fibers using up to tens of thousands of machines operating in parallel. It is also relevant to note how clean molecular manufacturing is expected to be-while these systems would manufacture products to atomic specification, they would also prepare waste products to atomic specification. Water vapor and carbon dioxide would be typical wastestream constituents. 

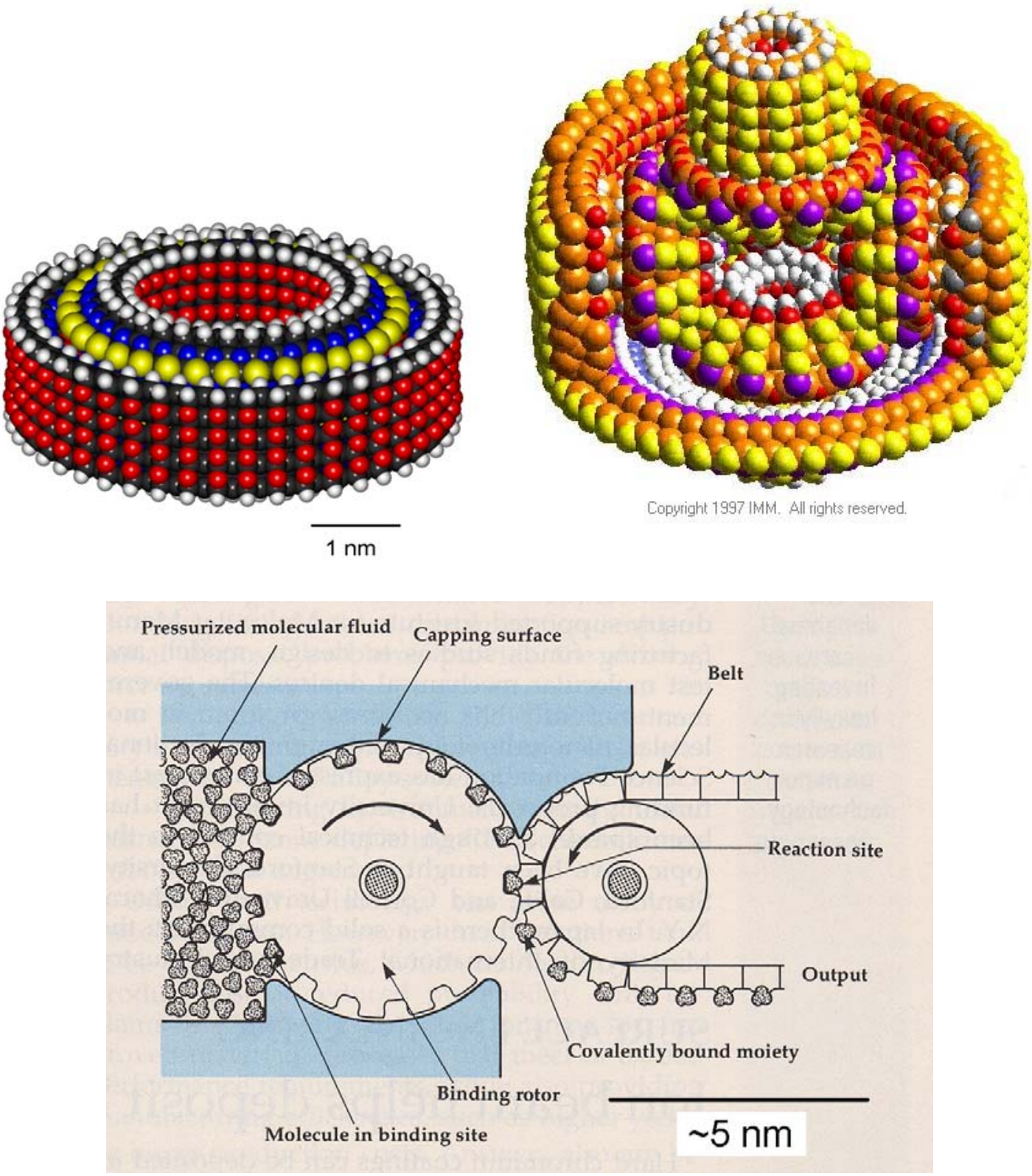

Figure1. Molecular mechanical components of increasing size and complexity. Electromechanical systems will be constructed at the molecular scale, including: support structures, rods, shafts, gears, bearings, conveyors, nanomotors, and manipulators. With proper design and built to atomic specification and precision, sliding surfaces would have low friction and gears and nanomotors would have high power conversion efficiency. The designs shown employ C, H, O, S and N atoms. Sources: K.E. Drexler, Nanosystems [5], and the Institute for Molecular Manufacturing (www.imm.org). 

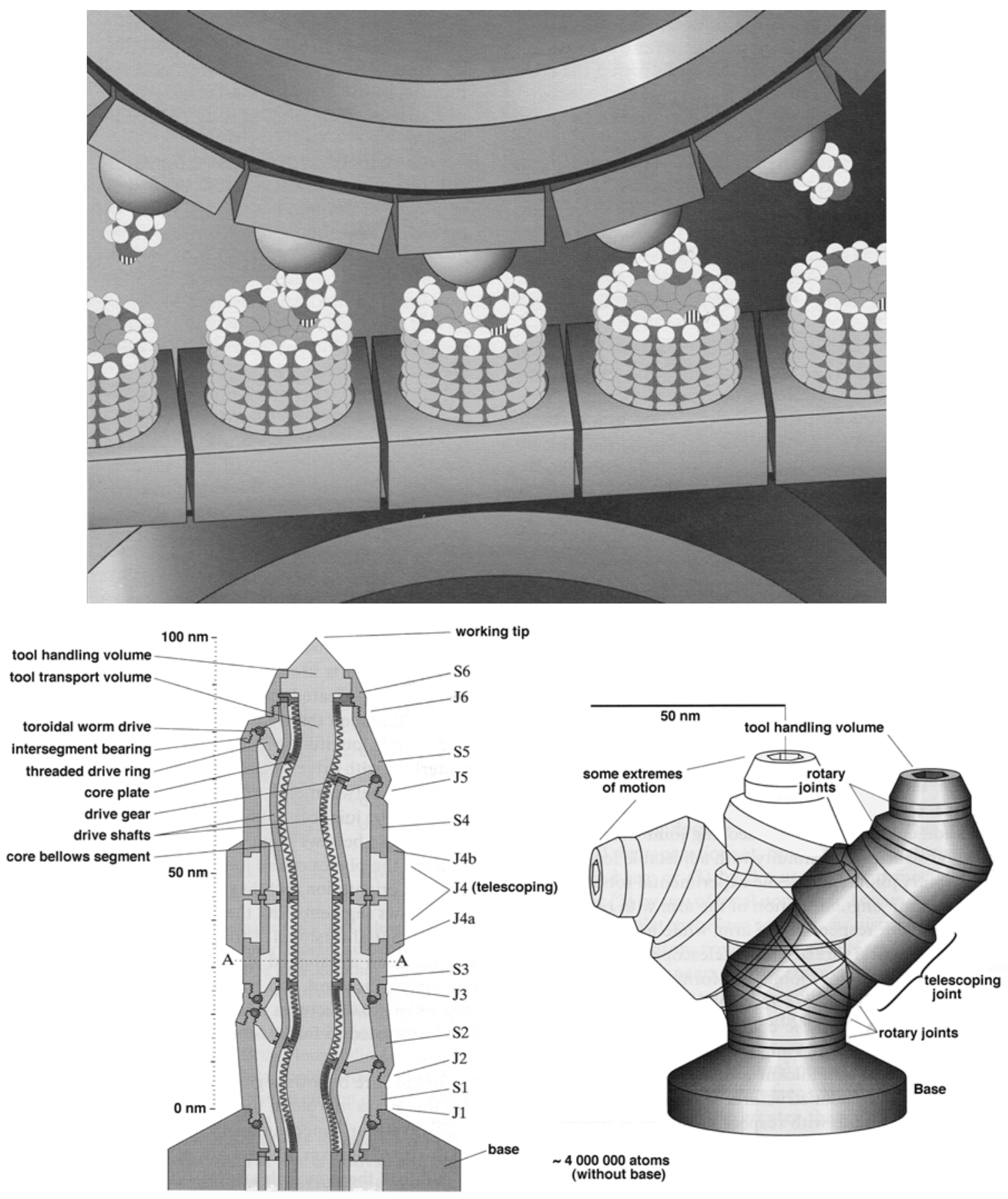

Figure 2. Molecular mills and molecular positioners. Molecular mills (top) would be used for high speed fabrication of highly redundant components. In this illustration a hydrogen atom (striped) is being added to a sleeve bearing as it passes by on a conveyor (which is not drawn to atomic detail). Molecular positioning arms (bottom) would be used to fabricate more customized components. At the nanoscale, megahertz rates of atomic placement are typical and estimates of system performance show that a four million atom manipulator arm (top) could make a copy of itself in less than 10 seconds. This is consistent with the known molecular processing speeds of enzymes in biological systems. Sources: K. E. Drexler, Nanosystems [5], and Institute for Molecular Manufacturing (www.imm.org). 


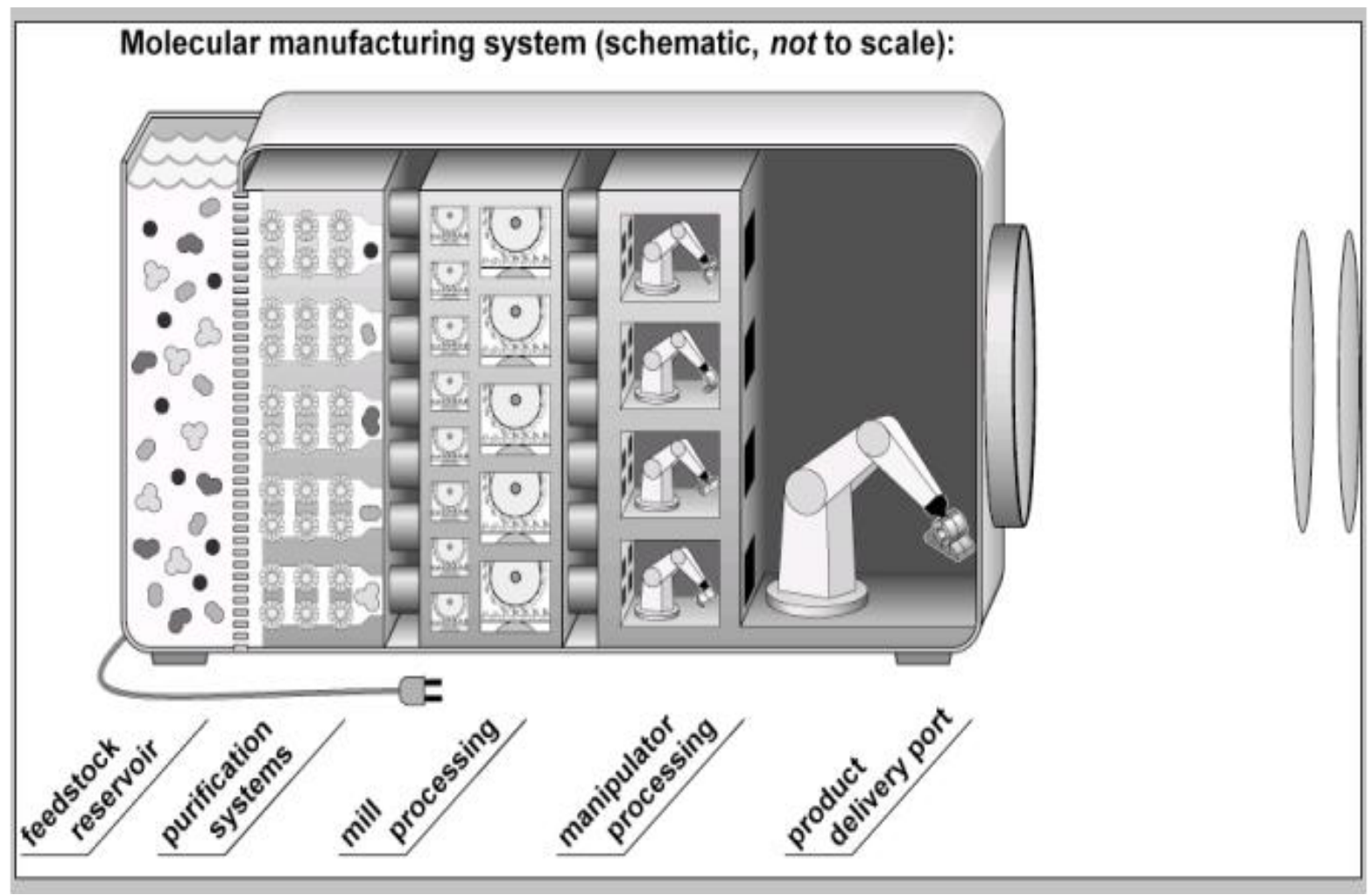

Figure 3. The desktop assembler concept. An exemplar $1 \mathrm{~kg}$ desktop assembler would produce atomically exact products at a rate of $1 \mathrm{~kg} / \mathrm{hr}$, would have a waste product of 1.5 $\mathrm{kg} / \mathrm{hr}$ of high purity water, and generate $3.6 \mathrm{~kW} / \mathrm{hr}$ excess power along with $1.1 \mathrm{~kW} / \mathrm{hr}$ of waste heat (from the release of energy from breaking bonds of inexpensive feedstock molecules). One product of the desktop assembler would be a copy of itself, but the system could be reprogrammed to synthesize other items such as food, clothing, or computers. Source: Institute for Molecular Manufacturing (www.imm.org).

\section{STATE OF THE ART}

In recent years there have been significant theoretical and experimental advances in molecular technologies that are enabling the development molecular manufacturing. Here, we focus on key experimental advances, which are summarized in Tables 1-3. Table 1 provides examples of advances in molecular construction. In 1999 Ho and Lee achieved the first documented instance of positional molecular assembly in a nonbiological system, when they picked up a single molecule of carbon monoxide, positioned it over a single atom of iron, and applied a voltage to force a chemical bond to occur between the Fe and CO. Ruoff and Banhart employed electron beams to bind carbon nanotubes to each other and to an atomic force microscope tip, demonstrating a successful joining technique.

Table 2 lists some advances in molecular electronic device development. The 1991 discovery of the carbon nanotube, and subsequent investigations that revealed its novel electronic properties, provided the groundwork for the stunning achievement of the demonstration of a molecular electronic memory based on carbon nanotubes in 2001 by Stan William's group at Hewlett Packard. 
Molecular motors are ubiquitous in biological systems (for example, bacterial flagella, or the actin/myosin in our own muscle tissue). Table 3 provides examples showing that we can co-opt a biological motor and attach it to inorganic devices (Montemagno), and create a fully synthetic molecular motor based on a nested carbon nanotube bearing (Zettl). Nested carbon nanotubes can also serve as a telescoping arm; Van der Vaals forces provide a restoring force that cause an extended tube to retreat back to its original position.

\begin{tabular}{|l|l|l|l|}
\hline \multicolumn{5}{|c}{ Table 1. Experimental Advances in Molecular Construction } \\
\hline 1999 & $\begin{array}{l}\text { Ho and Lee (Cornell U.) used a scanning tunneling } \\
\text { microscope to pick up a single carbon monoxide } \\
\text { molecule and chemically bind it to a single iron } \\
\text { atom by applying a voltage [7] (see picture, right). } \\
\text { This proved the concept of positional assembly } \\
\text { using a non-biological robotic system. }\end{array}$ \\
\hline 2000 & $\begin{array}{l}\text { Ruoff's group (Northwestern U.) used an electron } \\
\text { beam to attach individual nanotubes to cantilevers, } \\
\text { then measured their tensile strength (up to 63 GPa) } \\
\text { [8]. }\end{array}$ \\
\hline 2001 & $\begin{array}{l}\text { Banhart's group (U. of Ulm, Germany) used an } \\
\text { electron beam to attach individual nanotubes to } \\
\text { each other [9]. }\end{array}$
\end{tabular}

Research Initiatives in the US. In 1993 Rice University announced the first laboratory in the U.S. dedicated to nanotechnology research, and since then several dozen institutions worldwide have established their own dedicated centers. In $1996 \mathrm{Jim}$ Von Ehr formed Zyvex, the first molecular nanotechnology company. Their goal is to develop the technology and build self-replicating molecular assemblers. Other nanotechnology companies have since been established (or divisions created within larger companies), many focused on (1) molecular electronic devices for computer applications, (2) the synthesis of carbon nanotubes and other fullerenes, and (3) the synthesis of inorganic nanoparticles. In 2000, President Clinton announced the National Nanotechnology Initiative (NNI) with a doubling of funding on nanotechnology research to about $\$ 500$ million annually. This move cemented the already growing interest in nanotechnology in the United States, and there are similar new initiatives in Europe, Japan, and China. The NNI FY2004 funding level is \$847M. 


\begin{tabular}{|c|c|c|}
\hline 1996 & \multicolumn{2}{|c|}{ The first conductivity measurements of single molecules using an STM [10]. } \\
\hline 1997 & \multicolumn{2}{|c|}{$\begin{array}{l}\text { - The first measurement of electronic conduction in a single molecular wire } \\
\text { [11]. } \\
\text { - The electrical conductivity of carbon nanotubes was demonstrated. } \\
\text { - The first molecular diodes were synthesized }[12,13] \text {. }\end{array}$} \\
\hline 1998 & \multicolumn{2}{|c|}{ Carbon nanotube transistors were made and characterized. } \\
\hline 1999 & \multicolumn{2}{|c|}{$\begin{array}{l}\text { Reversible molecular switches were synthesized and tested (Hewlett Packard/UCLA, } \\
\text { Yale/Rice) }\end{array}$} \\
\hline 2001 & $\begin{array}{l}\text { Stan Williams' group at Hewlett Packard } \\
\text { demonstrated a 64-bit molecular electronic } \\
\text { memory [14]. }\end{array}$ & \\
\hline 2004 & \multicolumn{2}{|c|}{$\begin{array}{l}\text { Target year for completion of a DARPA-funded } 16 \text { kilobit molecular electronic } \\
\text { memory }\left(10^{11} \mathrm{bits} / \mathrm{cm}^{2}\right) \text {, now under development [15]. }\end{array}$} \\
\hline
\end{tabular}

Table 3. Experimental Advances in Molecular Electromechanical Devices

\begin{tabular}{|l|l|}
\hline 1999 & $\begin{array}{l}\text { Carlo Montemagno and George Bachand (Cornell) created the first organic/inorganic } \\
\text { integrated molecular motor, using a molecule of the enzyme ATPase coupled to a } \\
\text { metallic substrate with a genetically engineered handle. [16] }\end{array}$ \\
\hline 2001 & $\begin{array}{l}\text { Alex Zettl's group at Lawrence Berkeley } \\
\text { Laboratories developed a nearly frictionless } \\
\text { cylindrical molecular bearing (that can also } \\
\text { serve as a telescoping arm) based on nested } \\
\text { carbon nanotubes [17]. }\end{array}$ \\
\hline 2003 & $\begin{array}{l}\text { Alex Zettl's group at UC Berkeley } \\
\text { developed an electrostatic motor using } \\
\text { electron beam lithography to pattern a 100- } \\
300 \text { nm gold rotor suspended with a carbon } \\
\text { nanotube bearing [18]. }\end{array}$ \\
\hline
\end{tabular}




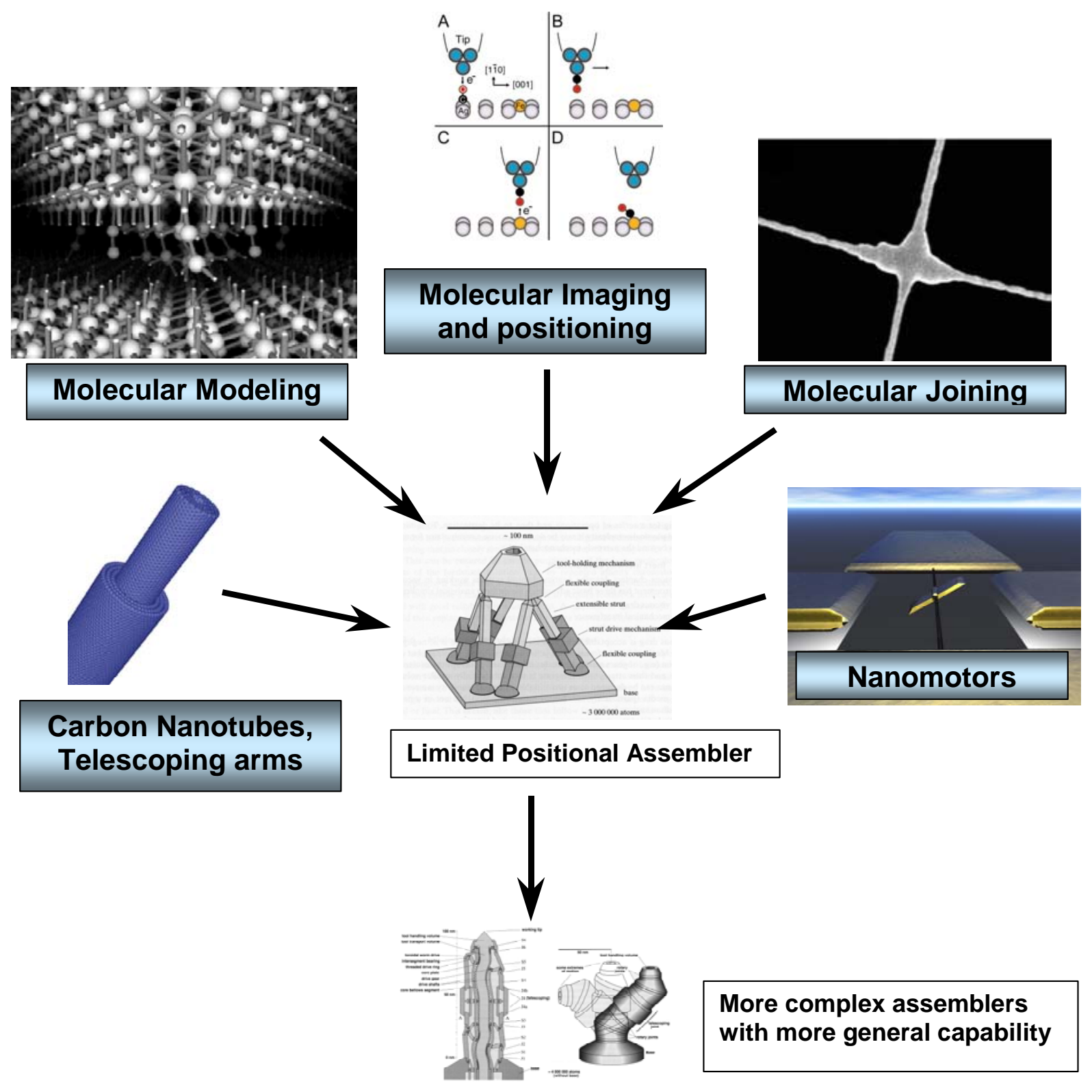

Figure 4. An illustration of the technological advances that are leading to the development of molecular robotic positioning systems [5, 7, 9, 17, 18, 27].

Figure 4 summarizes recent advances in molecular technologies that have now provided many of the building blocks and construction methods needed to build a positional assembler: structural members, sliding and rotating parts, motors, and positioning and joining technology. Carbon nanotubes, which have been commercially available for several years, can serve as strong, stiff, structural members. They can be joined with electron beams. Individual molecules can be positioned and joined to structures with a scanning tunneling microscope. Nested carbon nanotubes can serve as both cylindrical bearings and telescoping arms. An electrostatic nanomotor has also been created and tested. Molecular modeling techniques can be used to analyze designs prior to construction, further speeding the development process. Crude, less capable assemblers, 
coupled with continuing advances to make molecular electromechanical components, would lead to more highly advanced molecular assembler systems with broader capabilities.

\section{TIMEFRAME}

Molecular manufacturing R\&D, and indeed all technological progress, is proceeding at an accelerating pace. This has been quantified by Ray Kurzweil, who has shown that the rate doubles every decade [19]. In the next ten years we will perform the equivalent of twenty years worth of research at today's rate of progress, and the next century will see the equivalent of 20,000 years of progress (measured against today's rate). Double exponential growth curves are not intuitive, rendering even the best timeframe guesses by leading experts wrong by orders of magnitude. We can avoid these guesswork errors to some extent by focusing on trendlines for several technologies related to the one of interest. Trendlines for rates of advance in the distinct fields of precision machining and microlithography point to the mass production of atomically exact mechanical structures and computer chips around the year 2015 [20, 21]; Kurzweil's trendline (Figure 5, below) includes the advent of molecular mechanical devices a few years ago. Given (a) the trendlines for electronic and mechanical devices, (b) the current state of the art, especially the fact that the first robotically-controlled positional molecular assembly was demonstrated in 1999, and (c) these more general increasing rates of advance, the Institute for Molecular Manufacturing projects that a molecular assembler could be constructed by 2015.

Barriers to Progress. Despite promises of an economic revolution, and continuing successes in developing molecular robotic components, there are no large scale programs to develop molecular assembler systems. Part of the reason for this has been an ongoing debate in the U.S. about the feasibility of molecular assembly [22, 23], in which the basis for the technology has been brought into question. This may have been exacerbated by Bill Joy’s Wired article, “Why the future doesn't need us,” [24] in which he advocated ceasing research on molecular nanotechnology because of its potential dangers. Threatened with the spectre of losses in funding for all nanotechnology-related research, it was easier to deny the technology completely and marginalize Bill Joy than to clarify the distinctions between various kinds of nanotechnology research and address any dangers directly. European nations seem less concerned about this controversy. For example, in its market analysis Deutsche Bank AG identified molecular manufacturing as one of only three areas of high growth development in nanotechnology [25].

One concern about the ramifications of this debate is that, although development will progress with or without an integrated approach to developing molecular assembler systems, needed safeguards may be omitted without a concomitant focus on proper systems engineering. 


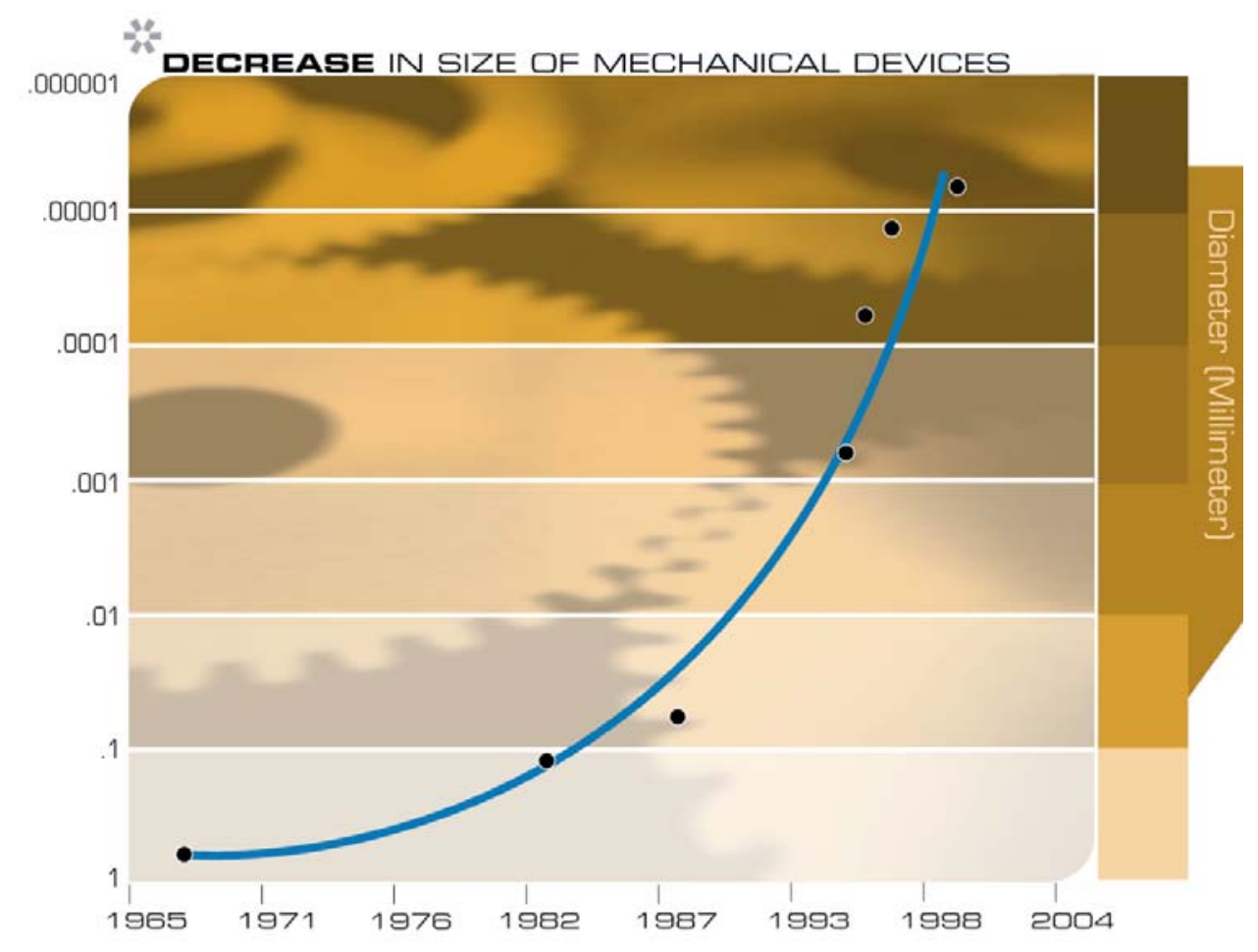

EXPONENTIALSCALE

Figure 5. The double exponential decrease in the size of mechanical devices over time (scale is in millimeters). The advent of molecular mechanical devices occurred roughly where the curves intersects $10^{-}$ ${ }^{5} \mathrm{~mm}$ (or 10nm--the diameter of a nested carbon nanotube). Illustration courtesy Ray Kurzweil, KurzweilAI.net.

\section{IMPLICATIONS FOR TEXTILES}

There are clear advantages to having materials that are 100 times stronger than we have now. Objects made from these materials could be up to 100 times lighter, using 100 times less material. As a result, ultralight cars, trucks, trains, and planes would use far less energy, especially with atomically smooth surfaces on moving parts and aerodynamic surfaces to reduce internal friction and air resistance losses.

Textiles will have similar gains in performance. Today, basic units of fabrics are molecules of natural and synthetic materials such as cotton (cellulose), wool ( $\alpha$-keratins), rayon (cellulose), and polyester. Bundles of these molecules are twisted to form fibers, which can be spun into threads and yarns. An obvious way to strengthen these conventional materials would be to reinforce them with carbon nanotubes-the current darling of nanotechnology materials. In fact there are already intensive efforts by groups around the world to create fibers from carbon nanotubes, which individually have a tensile strength of about $100 \mathrm{GPa}$. This is more than 50 times stronger than a typical steel and $1 / 3$ the density. By comparison, commercial rayon has a tensile strength of $0.45 \mathrm{GPa}$ and nylon, $0.08 \mathrm{GPa}$.

One of the difficulties in using carbon nanotubes in textiles is that it is difficult to grow nanotube molecules into centimeter lengths without loss of strength (due to processing- 
induced defects in long molecules). It's also difficult to twist shorter nanotubes into a fiber while maintaining the high strength of the individual nanotube. With molecular manufacturing, arbitrarily long nanotubes would be possible, and textiles could be fabricated to nearly their theoretical strengths.

Carbon nanotubes also have a high thermal conductivity along the axis (about three times that of diamond, and 15 times that of copper). Like diamond, carbon nanotubes are very stable in air to $1000^{\circ} \mathrm{C}$. With these properties, a carbon-nanotube-based textile would make an excellent heat resistant fabric. The high axial thermal conductivity would act as a natural heat pipe to help to dissipate energy from hot spots on the material. Thermal conductivity could be quite low in the transverse plane with an open array of molecules with long, widely spaced cross-links.

Today's textile materials made with molecular manufacturing would be considerable stronger. The theoretical strength of cellulose is 12-19 GPa, so the strength of cotton and rayon could be improved more than ten-fold with molecular manufacturing. As Roger Soderberg has pointed out, there would be virtually $100 \%$ efficiency in converting yarns to fabric tensile strength due to the high level of uniformity in both strength and elongation from one yarn to another [26] . Fiber separation could be eliminated as a failure mode by connecting individual fibers end to end and making them continuous, but still bundled and twisted in the same amorphous way. It seems possible to do this while maintaining the look and feel of current fabrics, if desired.

\section{Smart materials and nanotechnology}

While synthesis of defect-free materials will lead to substantial improvements in performance, molecular nanotechnology will make more radical changes possible by integrating computers, sensors, and micro- and nanomachines with materials. Here are some ideas:

- Micropumps and flexible microtubes could transport coolant or a heated medium to needed parts of clothing.

- The kinds of sorting rotors shown in Figure 1 could be arrayed as "pores" in a semi-permeable membrane to allow only particular kinds of molecules through. Water might be a useful molecule to select for, to keep one side of a fabric dry or another side wet. On the wet side, the water could be transported away to an evaporator, or stored.

- Active, programmable materials. A rich integration of sensors, computers, and actuators within structural materials will blur the distinction between materials and machines, allowing the design and construction of objects that can be programmably reconfigured to sub-micron precision. These materials could monitor and report on their own state of "health." Figure 6 illustrates this concept with a latticework of machines linked by telescoping, interlocking arms. Both information and power would be transmitted through the arms to the individually addressable nodes. By selecting which screws would tighten and which would loosen, the shape of a item could change to conform to the needs of the user. A solid, rigid 
object could be made to behave like a fabric by effecting rapid changes in its shape, or with temporary disconnections between some cells. A flexible fabric could turn rigid by having loosely bound cells connect into a stiff framework. Thus, distinctions between fabrics and other types of rigid materials could blur.

The programmable material concept is not limited to fabrics but has many potential applications there. One example that Drexler pointed out would be a space suit that would allow nearly as much freedom of movement as one's own skin. Imbedded computers connected to strain gages could sense the wearer's intended movement and adjust the material accordingly. Reflectance of the outer layer could be variable to absorb needed amounts of heat from the sun-facing side and transport it to cold spots-although the material's insulative properties would allow very little of the wearer's heat to escape. Excess heat could be transported to radiators on the cold side.
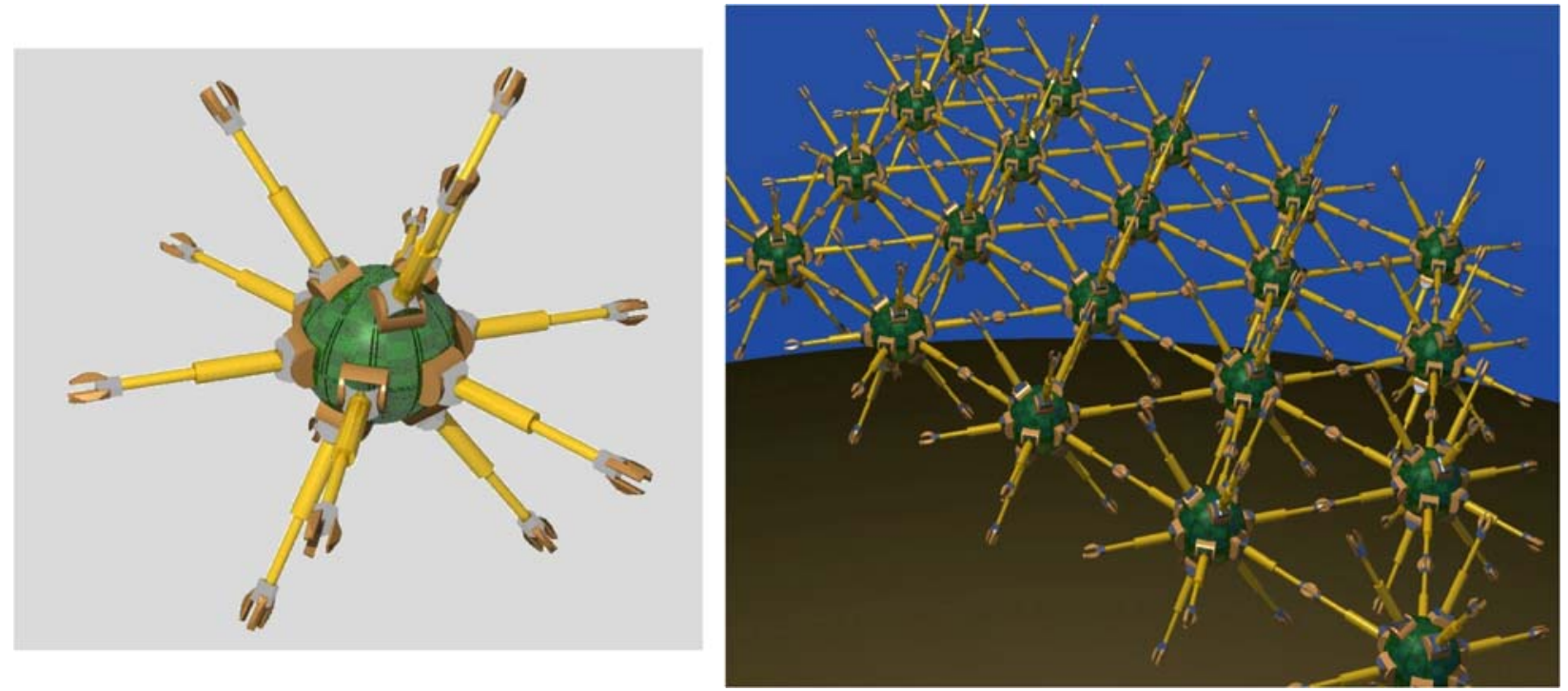

Figure 6. An individual node (left) and a 2D array of interlocked nodes (right). Materials made from these devices could be instructed to change their shape in rapid fashion. Illustration by J. Storrs Hall, Institute for Molecular Manufacturing.

- Fabrics could be self-cleaning: robotic devices similar to mites could periodically scour the fabric surfaces and integral conveyors could transport the dirt to a collection site, or the previously mentioned molecule-selective membrane could transport water to one side or the other for a cleaning rinse.

- Fabrics could be self-repairing: sensors would detect discontinuities in the material via loss of signal or a reported strain overload and send robotic "crews" to repair the damage. Self-shaping fabrics would be able to return to their original shape around a tear until repairs are effected. 
- Large sections of fabrics could be made without visible seams by joining panels of fabric with microscopic mechanical couplings along their edges. Similarly, surfaces could contain mechanical couplings that, when pressed together would bond with nearly the strength of the bulk material. This 'smart velcro' could latch and unlatch at the user's request.

\section{SUMMARY}

Molecular manufacturing is an emerging technology that is being developed to build large objects to atomic precision, quickly and cheaply, with virtually no defects. In recent years, molecular manufacturing has progressed from theoretical studies to the construction of working molecular machine components. Positional molecular assembly has been demonstrated in the laboratory, and a potentially useful artificial molecular motor has been synthesized and tested. One company, Zyvex, has announced its intention to design and build a molecular assembler, and many companies are designing and building molecular computer components. Molecular transistors have been built and tested, and a working molecular electronic memory unit has been demonstrated.

Much work remains before molecular robots begin assembling machine components, ushering in the era of molecular manufacturing. But when molecular manufacturing matures, probably by the year 2015, it promises to be an inexpensive, energy efficient, and environmentally benign way to make a new generation of advanced textiles. 


\section{REFERENCES}

1. Feynman, R.P., "There's Plenty of Room at the Bottom,” Engineering and Science, 23 (1960): 22-36.

2. http://www.e-drexler.com/

3. Drexler, K.E., "Molecular engineering: An approach to the development of general capabilities for molecular manipulation,” Proc. Natl. Acad. Sci. USA, 78 (9) (September 1981): 5275-5278. (http://www.imm.org/PNAS.html)

4. Drexler, K. E., “Engines of Creation,” Doubleday, Garden City, NY (1986). (http://www.foresight.org/EOC/)

5. Drexler, K.E., Nanosystems: Molecular Machinery, Manufacturing, and Computation, John Wiley \& Sons, Inc.: New York (1992). See http://www.foresight.org/Nanosystems/

6. Forrest, D.R., "Molecular Machines for Materials Processing," Advanced Materials \& Processes, 141 (1), (Jan. 1993).

7. Ho and H.J. Lee "Single-Bond Formation and Characterization with a Scanning Tunneling Microscope," Science, 286 (1999): 1719-1722.

8. Yu MF, Lourie O, Dyer MJ, Moloni K, Kelly TF, and Ruoff RS, "Strength and breaking mechanism of multiwalled carbon nanotubes under tensile load,” Science, 287 (2000): 637-640.

9. T. Smalley-Brown, "Electron Beam Welds Nano-tubes," Technology Research News, August 1/8, 2001. http://www.trnmag.com/Stories/080101/Electron_beam_welds_nanotubes_080101.html

10. L. A. Bumm, J. J. Arnold, M. T. Cygan, T. D. Dunbar, T. P. Burgin, L. Jones II, D. L. Allara, J. M. Tour, and P. S. Weiss, "Are single molecular wires conducting?" Science, 271 (1996): 17051706.

11. M. A. Reed, C. Zhou, C. J. Muller, T. P. Burgin, and J. M. Tour, Science, 278 (1997): 252.

12. R. M. Metzger, B. Chen, U. Höpfner, M. V. Lakshmikantham, D. Vuillaume, T. Kawai, X. Wu, H. Tachibana, T. V. Hughes, H. Sakurai, J. W. Baldwin, C. Hosch, M. P. Cava, L. Brehmer, and G. J. Ashwell, "Unimolecular electrical rectification in hexadecyl-quinolinium tricyanoquinodimethanide," J. Amer. Chem. Soc., 119, (1997): 10455-10466.

13. C. Zhou, M. R. Deshpande, M. A. Reed, L. Jones, II, and J. M. Tour, "Nanoscale metal/selfassembled monolayer/metal heterostructures," Appl. Phys. Lett., 71, (1997): 611.

14. Berman, D., "Beyond silicon: hp researchers announce breakthroughs in molecular electronics," Sept. 2002. http://www.hp.com/hpinfo/newsroom/feature stories/2002/molecular02.html

15. http://www.darpa.mil/mto/solicitations/BAA03-12/S/Section1.html

16. Montemagno, C. D., and Bachand, G. D. 1999. "Constructing nanomechanical devices powered by biomolecular motors." Nanotechnology 10: 225-331.

17. http://www.lbl.gov/Science-Articles/ResearchReview/Magazine/2001/Fall/features/02Nanotubes.html

18. A. M. Fennimore, T. D. Yuzvinsky, Wei-Qiang Han, M. S. Fuhrer, J. Cumings, and A. Zettl, "Rotational actuators based on carbon nanotubes," Nature 424 (July 24): 408-410. See also http://www.berkeley.edu/news/media/releases/2003/07/23 motor.shtml http://www.berkeley.edu/news/media/releases/2003/07/video/nano bband.mov

19. http://www.kurzweilai.net/meme/frame.html?main=/articles/art0134.html

20. Keyes, R.W., "Miniaturization of electronics and its limits," IBM Journal of Research and Development, 32 (1) (Jan. 1988): 24-28.

21. Taniguchi, N., "Future Trends of Nanotechnology," International Journal of the Japan Society for Precision Engineering, 26 (1) (March 1992): 1-7.

22. A Debate About Assemblers (2001). http://www.imm.org/SciAmDebate2/index.html

23. Rudy Baum, "Nanotechnology: Drexler and Smalley make the case for and against 'molecular assemblers,"” Chemical \& Engineering News, 81 (48) (1 Dec 2003): 37-42. http://pubs.acs.org/cen/coverstory/8148/8148counterpoint.html

24. Forrest, D. R., "Perspectives on Nano2002:the Sixth International Conference on Nanostructured Materials," 16-21 June 2002. http://www.nanoindustries.com/feature/Nano2002.html

25. Joy, Bill, “Why the future doesn’t need us,” Wired, 8.04, April 2000. http://www.wired.com/wired/archive/8.04/joy.html

26. Personal correspondence with Soderberg, R., 18 August 1995.

27. D. W. Brenner, S. B. Sinnott, J. A. Harrison, O. A. Shenderova, "Simulated engineering of nanostructures," Nanotechnology 7 (1996): 161-167. http://www.zyvex.com/nanotech/nano4/brennerPaper.pdf 